\title{
Genome-wide microarray analysis of tomato roots showed defined responses to iron deficiency
}

\author{
Anita Zamboni ${ }^{1 \dagger}$, Laura Zanin ${ }^{2 \dagger}$, Nicola Tomasi ${ }^{2}$, Mario Pezzotti ${ }^{1}$, Roberto Pinton ${ }^{2}$, Zeno Varanini ${ }^{1 *}$ and \\ Stefano $\mathrm{Cesco}^{3}$
}

\begin{abstract}
Background: Plants react to iron deficiency stress adopting different kind of adaptive responses. Tomato, a Strategy / plant, improves iron uptake through acidification of rhizosphere, reduction of $\mathrm{Fe}^{3+}$ to $\mathrm{Fe}^{2+}$ and transport of $\mathrm{Fe}^{2+}$ into the cells. Large-scale transcriptional analyses of roots under iron deficiency are only available for a very limited number of plant species with particular emphasis for Arabidopsis thaliana. Regarding tomato, an interesting model species for Strategy / plants and an economically important crop, physiological responses to Fe-deficiency have been thoroughly described and molecular analyses have provided evidence for genes involved in iron uptake mechanisms and their regulation. However, no detailed transcriptome analysis has been described so far.

Results: A genome-wide transcriptional analysis, performed with a chip that allows to monitor the expression of more than 25,000 tomato transcripts, identified 97 differentially expressed transcripts by comparing roots of Fedeficient and Fe-sufficient tomato plants. These transcripts are related to the physiological responses of tomato roots to the nutrient stress resulting in an improved iron uptake, including regulatory aspects, translocation, root morphological modification and adaptation in primary metabolic pathways, such as glycolysis and TCA cycle. Other genes play a role in flavonoid biosynthesis and hormonal metabolism.

Conclusions: The transcriptional characterization confirmed the presence of the previously described mechanisms to adapt to iron starvation in tomato, but also allowed to identify other genes potentially playing a role in this process, thus opening new research perspectives to improve the knowledge on the tomato root response to the nutrient deficiency.
\end{abstract}

\section{Background}

Iron $(\mathrm{Fe})$ deficiency is a yield-limiting factor for a variety of field crops all around the world and generally results from the interaction of limited soil Fe bioavailability and susceptible genotype cultivation [1]. Iron is an important microelement for plant life due to its involvement as redox-active metal in photosynthesis, mitochondrial respiration, nitrogen assimilation, hormone biosynthesis, production and scavenging of reactive oxygen species, osmoprotection and pathogen defence [2].

Under aerated conditions at neutral alkaline $\mathrm{pH}$, the soluble Fe concentration in soil solution is very low. To cope with Fe shortage plants have developed two

\footnotetext{
* Correspondence: zeno.varanini@uniud.it

† Contributed equally

'Department of Biotechnology, University of Verona, via delle Grazie 15,

37134 Verona, Italy

Full list of author information is available at the end of the article
}

strategies for its acquisition. The Strategy I (all higher plants except grasses) relies on improvement of Fe uptake through acidification of soil solution by excretion of protons via a plasmalemma P-type ATPase resulting in an increased Fe solubility, reduction of $\mathrm{Fe}^{3+}$ to the more soluble $\mathrm{Fe}^{2+}$ by a $\mathrm{Fe}^{\mathrm{III}}$-chelate reductase and plasmalemma transport of $\mathrm{Fe}^{2+}$ by the activity of a Fe transporter [3]. Some model plants used to study Strategy I are dicots such as Arabidopsis thaliana, Solanum lycopersicum and Pisum sativum [4].

Plant responses to Fe deficiency have been recently analyzed on the basis of large-scale changes not only in transcriptome [5-14], but also in proteome [15-20] and metabolome [17]. Results of transcriptome analysis are influenced by differences in experimental plans, plant species and microarray platforms, and thus difficult to compare and be generalized. Notwithstanding this drawback, recently, a set of 92 transcripts that robustly

\section{Biomed Central}


reflect the transcriptional response of Arabidopsis to Fe deficiency [21], has been described as the "ferrome" by Schmidt and Buckhout [21]. The "ferrome" consists of a list of transcripts considered to be involved in the basic response to iron deficiency. The ferrome is particularly enriched in genes related to heavy metal cation transport and metal homeostasis. Focusing on tomato, a plant often used as a model to study Fe deficiency (Strategy I) and a crop of economic importance, no information is available at genome-wide transcriptional level. Two proteomic characterizations of tomato roots in response to 1-week of Fe deprivation showed 23 [15] and 15 [16] differentially expressed protein spots respectively. Modifications in proteome suggest changes in energy metabolism, sulfur metabolism, response to oxidative stress and signal transduction.

In the present work a genome-wide transcriptional characterization of tomato roots in response to Fe deficiency is presented. This approach allowed indentifying 97 differentially expressed transcripts involved in the responses to the nutritional stress. Transcriptional changes, mainly related to positive modulation of glycolysis, TCA and methionine cycle, suggest that tomato roots behave similarly to Arabidopsis under Fe deficiency. Furthermore, flavonoid biosynthesis and root morphological changes are revealed as specific tomato responses to Fe shortage.

\section{Results and discussion}

\section{Responses to Fe-deficiency}

Typical responses of Fe-deficiency [22] were observed in tomato plants grown for $14 \mathrm{~d}$ in the presence of a low amount of Fe and thereafter subjected to $7 \mathrm{~d}$ of Fe deprivation. The chlorophyll content (SPAD index value) was reduced in Fe-deficient plants (Table 1). A concomitant increase in root $\mathrm{Fe}^{\mathrm{III}}$-chelate reductase activity (Table 1) was also observed with values similar to those commonly found in roots of Fe-deficient tomato plants [23]. Furthermore, Fe-deprived tomato plants developed more lateral roots and showed an abundant production of root-hairs (Figures 1 and 2).

Table 1 Leaf SPAD index values and root Fe ${ }^{\text {I'I-chelate }}$ reductase activity

\begin{tabular}{|c|c|c|}
\hline Sample & $\begin{array}{l}\text { SPAD } \\
\text { index }^{a}\end{array}$ & $\begin{array}{l}\mathrm{Fe}^{\mathrm{III}} \text {-chelate reductase }\left(\mathrm{mol} \mathrm{g}^{-1} \text { root } \mathrm{FW}\right. \\
\left.\mathrm{h}^{-1}\right)^{\mathbf{b}}\end{array}$ \\
\hline $\begin{array}{l}\text { Fe- } \\
\text { sufficient }\end{array}$ & $29.5 \pm 0.3$ & $0.37 \pm 0.04$ \\
\hline $\begin{array}{l}\text { Fe- } \\
\text { deficient }\end{array}$ & $16.8 \pm 0.6$ & $1.41 \pm 0.06$ \\
\hline
\end{tabular}

${ }^{a}$ SPAD index value of fully expanded young leaves was determined using a SPAD-502 meter (Minolta, Osaka, Japan); mean and SD using data of the three biological replicates.

${ }^{\mathrm{b}}$ Mean and SD of three biological replicates.

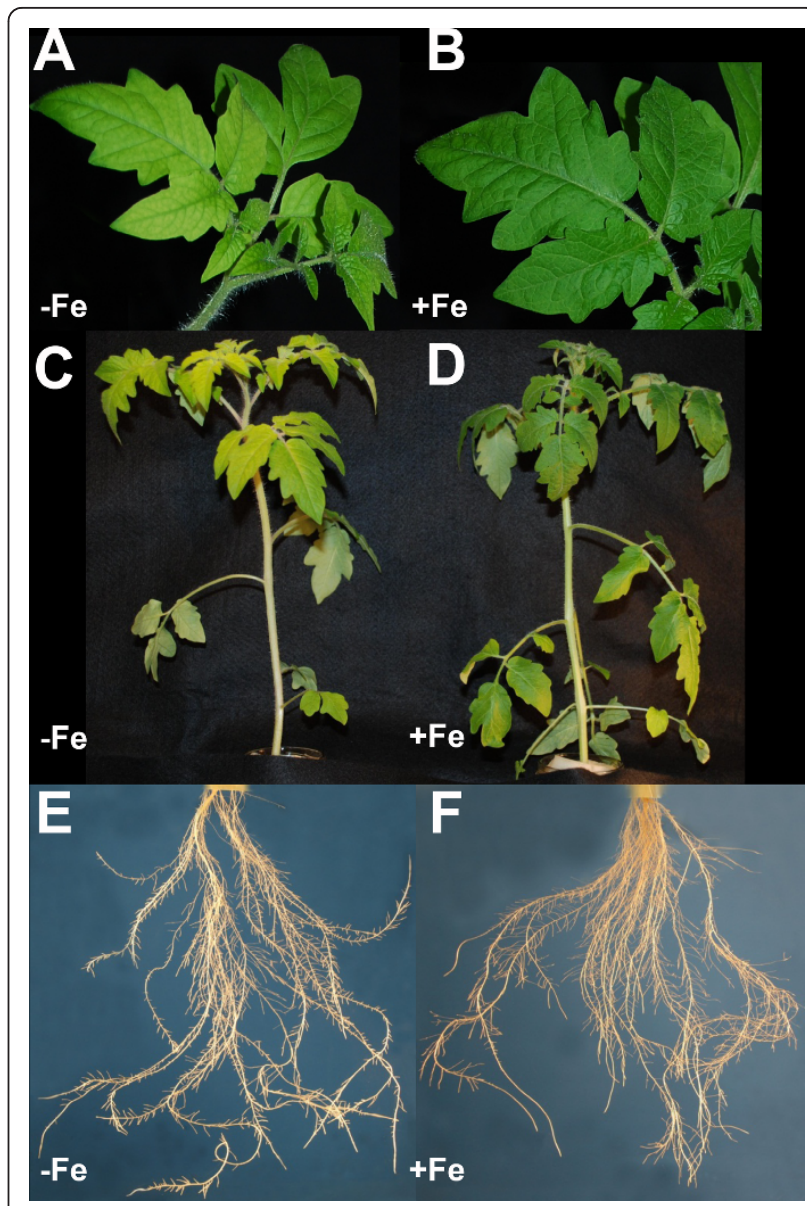

Figure 1 Shoot and root apparatus of tomato plants grown under different Fe-supply conditions. Leaf detail of Fe-deficient (A) and Fe-sufficient (B) plants. Shoot (C) and roots (E) of Fedeficient plants and shoot (D) and roots (E) of Fe-sufficient plants.

Comparison of root gene expression profiles in $\mathrm{Fe}$ deficient and Fe-sufficient tomato plants

Differences in root gene expression between Fe-sufficient and Fe-deficient tomato plants were obtained by a genome-wide gene expression analysis using a tomato chip developed through Combimatrix technology [24]. This chip allows monitoring simultaneously the expression of more than 25,000 tomato transcripts. Ninety-
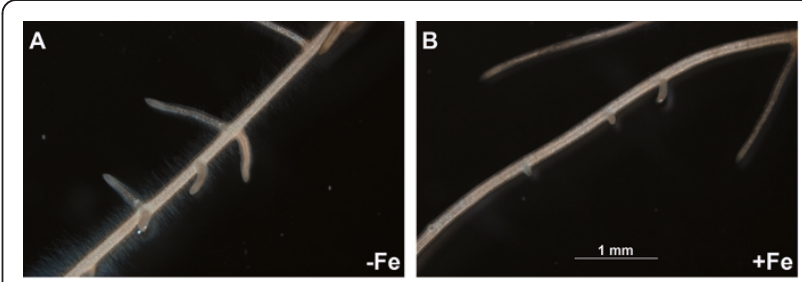

Figure 2 Root apparatus of tomato plants grown under different Fe-supply condition. Detail of root apparatus of A) Fedeficient and B) Fe-sufficient plants. 
seven differentially expressed transcripts between Fedeficient and Fe-sufficient tomato roots (75 up-regulated and 22 down-regulated) were identified by Linear Models for MicroArray (LIMMA) [25] (adjusted p-value $\leq$ $0.05 ;|F C| \geq 2$ ). This result obtained using a large-scale chip reinforce the idea that plant transcriptional response to Fe shortage is based on the modulation of a relative small set of genes as previously observed for the Arabidopsis "ferrome" [21].

Manually curated annotation of the 97 differentially expressed transcripts was based on results of BlastP analysis against UniProt [26] database (Figure 3; Additional file 1) using terms of biological process of Gene Ontology (GO) [27]. Sequence grouping in functional categories according to the $\mathrm{GO}$ terms revealed that the most abundant functional category was "metabolic process" both for up-regulated and down-regulated transcripts (35\% and 45\% respectively; Figure 3). Other upregulated transcripts belonged to "establishment of localization" (12\%) and "cell wall organization and biogenesis" (8\%), while for the down-regulated transcripts "response to stimulus" (9\%) was one of the most representative main functional categories (Figure 3). Only upregulated transcripts are present in the "secondary metabolic process" category (Table 2). Transcripts encoding proteins with no sequence homology to known proteins were defined as "no hits found" (12\% and 5\% for upregulated and down-regulated transcripts respectively), while a similar percentage of transcripts showed homology to proteins involved in "unknown" biological process $(24 \%$ and $23 \%$ respectively). A selection of differentially expressed and discussed in relation to Fe deficiency is reported in Table 2. The up-regulation and down-regulation of six differentially expressed transcripts in response to Fe deficiency were confirmed through Real-time RT-PCR experiments (Table 3).

$T C I D$, description, Real-time $R T-P C R$ relative expression value (Fe-deficient vs. Fe-sufficient) and microarray fold change value (Fe-deficient vs. Fe-sufficient). Real time data were normalized on the EF1a gene and were performed 4 times on 3 independent experiments. Realtime RT-PCR data are expressed as mean \pm SD.

Sixty-one of 97 transcripts are ascribable to adaptive responses to Fe deficiency involving Fe homeostasis, metabolic process, oxidative stress responses, root morphological modification, transport processes, hormone metabolism and signaling. The others are hardly related to specific role showing homology to protein without a specific biological process or lacking homology to known protein ("no hits found").

\section{Fe homestasis}

Our transcriptional analysis confirmed that roots of Fedeficient tomato plants overexpressed genes involved in Fe uptake and reduction, including the transcripts encoding IRON-REGULATED TRANSPORTER (IRT) [28-30] and $\mathrm{Fe}^{\mathrm{III}}$-chelate reductase (FRO) [31]. The tomato bHLH protein (encoded by LeFER) plays a role in Fe-deficiency responses through the expression of these two tomato Fe mobilization genes belonging to the Fe uptake systems of the Strategy I plants [29,32,33]. Our data show the up-regulation of the FER transcript $(\# 24)$ in Fe-deficient roots, which is in agreement with the positive modulation of Fe-uptake-related transcripts such as LeFRO1 (\#68), LeIRT1 (\#39) and a transcript encoding a NATURAL RESISTANCE-ASSOCIATED

\section{A}

\section{B}
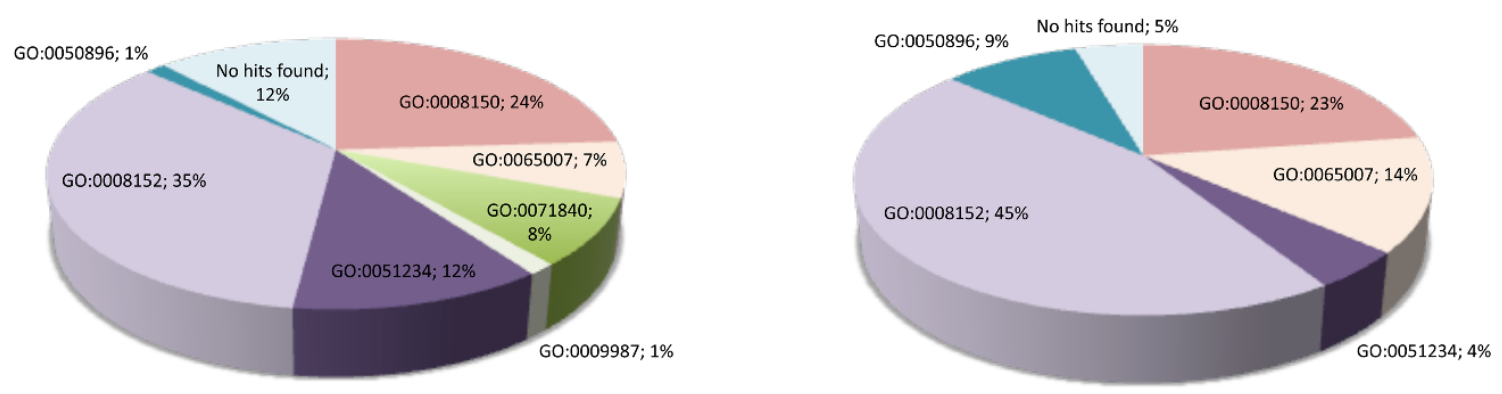

GO:0008150 biological process

GO:0008152 metabolic process

GO:0009987 cellular process

GO:0050896 response to stimulus

GO:0051234 establishment of localization

GO:0065007 biological regulation

GO:0071840 cellular component organization and biogenesis

Figure 3 Functional categories distribution of differentially expressed transcripts. Distribution in main functional categories according to the GO "biological process" terms of the 75 up-regulated (A) and 22 down-regulated (B) transcripts in roots of Fe-deficient relative to Fesufficient plants. Percentage of transcripts is reported for each functional category. 
Table 2 List of transcripts modulated in response to Fe-deficiency and reported in the Discussion

\begin{tabular}{|c|c|c|c|c|c|c|}
\hline$\#$ & ProbelD $^{a}$ & Description $^{\text {b }}$ & UniProtID $^{c}$ & $T C-I D^{d}$ & $\mathrm{FC}^{\mathrm{e}}$ & $p$, value, adj ${ }^{f}$ \\
\hline & \multicolumn{6}{|c|}{ Biological process GO:0008150 } \\
\hline 1 & TC192724_853_37_S & SRC2 & B6SND5 & TC192724 & 3.02 & 0.014 \\
\hline 2 & TC192763_241_40_S & Putative uncharacterized protein & С6Т3H9 & TC192763 & 2.11 & 0.030 \\
\hline 3 & TC193319_801_34_X2 & Putative uncharacterized protein & Q40127 & TC193319 & -3.35 & 0.016 \\
\hline 4 & TC195341_998_35_S & Putative uncharacterized protein & Q40127 & TC195341 & -3.33 & 0.011 \\
\hline 5 & TC196753_1279_37_S & D-protein & Q8VWY8 & TC196753 & 6.11 & 0.028 \\
\hline 6 & TC197095_638_34_X2 & NtEIG-E80 protein (elicitor inducible gene product) & Q9FXS6 & TC197095 & 4.69 & 0.024 \\
\hline 7 & TC198323_947_40_S & Predicted protein & B9MWQ1 & TC198323 & 2.51 & 0.032 \\
\hline 8 & TC199253_1439_39_S & Zinc finger protein. putative & B9SLY6 & TC199253 & 2.82 & 0.029 \\
\hline 9 & TC202360_487_40_S & EF-1 alpha-like protein & O49604 & TC202360 & 2.15 & 0.024 \\
\hline 10 & TC204571_463_40_S & ATBET12, putative & B9STJ3 & TC204571 & -2.62 & 0.023 \\
\hline 11 & TC205207_890_35_S & Putative uncharacterized protein & Q40127 & TC205207 & -3.09 & 0.048 \\
\hline 12 & TC207200_893_35_S & VIT_00038707001 & EOCVH7 & TC207200 & 2.44 & 0.042 \\
\hline 13 & TC207407_739_37_S & Predicted protein & B9HQW6 & TC207407 & 2.36 & 0.042 \\
\hline 14 & TC207665_362_36_S & Putative uncharacterized protein & A9PCS8 & TC207665 & -2.39 & 0.048 \\
\hline 15 & TC208712_583_40_S & Germin-like protein & Q5DT23 & TC208712 & 2.35 & 0.046 \\
\hline 16 & TC208745_692_37_S & Putative uncharacterized protein & A5COF7 & TC208745 & 4.84 & 0.016 \\
\hline 17 & TC209321_482_35_S & VITISV_041870 & A5C9V2 & TC209321 & 6.94 & 0.011 \\
\hline 18 & TC209504_302_40_S & Hydrolase & Q4PSL3 & TC209504 & 2.78 & 0.013 \\
\hline 19 & TC211515_728_35_S & Amino acid binding protein, putative & B9RBU8 & TC211515 & 3.66 & 0.014 \\
\hline 20 & TC212954_1137_35_S & Predicted protein & $\mathrm{B} 9 \mathrm{HZ} 36$ & TC212954 & 2.02 & 0.046 \\
\hline 21 & TC213456_100_34_S & Putative D-protein & Q6K482 & TC213456 & 4.97 & 0.035 \\
\hline 22 & TC214599_1004_37_S & Nodulin-like proteinAt2g16660/T24I21.7 & Q9SLF1 & TC214599 & 6.87 & 0.042 \\
\hline \multirow[t]{2}{*}{23} & TC215994_489_36_S & Putative aminotransferase, class $V$ family protein & Q1H8R9 & TC215994 & 2.08 & 0.036 \\
\hline & \multicolumn{6}{|c|}{ Biological regulation GO: 0065007} \\
\hline 24 & TC191806_907_40_S & BHLH transcriptional & Q5GA67 & TC191806 & 6.56 & 0.024 \\
\hline 25 & TC191963_1058_37_S & Ferritin & Q308A9 & TC191963 & -4.71 & 0.008 \\
\hline 26 & TC194645_664_37_S & DNA binding protein & B9SZX2 & TC194645 & 12.34 & 0.015 \\
\hline 27 & TC198138_1325_39_S & Thioredoxin peroxidase 1 & Q7Y240 & TC198138 & 7.06 & 0.046 \\
\hline 28 & TC203853_451_35_S & Heterogeneous nuclear ribonucleoprotein $27 \mathrm{C}$ & B9SSS5 & TC203853 & 2.90 & 0.028 \\
\hline 29 & TC206202_500_40_S & Thioredoxin II & B9RLX0 & TC206202 & -2.47 & 0.048 \\
\hline \multirow[t]{2}{*}{30} & TC215976_330_38_X2 & Ferritin & Q308A9 & TC215976 & -3.64 & 0.005 \\
\hline & \multicolumn{6}{|c|}{ Cellular component organization or biogenesis GO:0071840 } \\
\hline 31 & NP000231_1302_40_S & Extensin-like protein Dif54 & Q43505 & NP000231 & 8.22 & 0.011 \\
\hline 32 & TC191669_1238_40_S & Extensin-like protein Ext1 & Q8VWM5 & TC191669 & 5.53 & 0.003 \\
\hline 33 & TC204863_245_40_S & Extensin-like protein Ext1 & Q8WWM5 & TC204863 & 8.98 & 0.013 \\
\hline 34 & TC212258_415_40_S & Extensin-like protein Dif54 & Q43505 & TC212258 & 9.13 & 0.011 \\
\hline 35 & TC212487_279_40_S & Extensin-like protein Ext1 & Q8WWM5 & TC212487 & 6.44 & 0.0004 \\
\hline \multirow[t]{2}{*}{36} & TC214133_1133_40_S & Extensin-like protein Dif10 & Q43504 & TC214133 & 5.42 & 0.024 \\
\hline & \multicolumn{6}{|c|}{ Cellular process GO:0009987 } \\
\hline 37 & TC207486_546_40_S & Pollen specific actin-depolymerizing factor 2 & Q8H2B6 & TC207486 & 4.81 & 0.005 \\
\hline & \multicolumn{6}{|c|}{ Establishment of localization GO: 0051234} \\
\hline 38 & NP796451_1558_36_S & Root-specific metal transporter & Q84LR1 & NP796451 & 12.00 & 0.024 \\
\hline 39 & TC191581_1150_36_S & Iron-regulated transporter 1 & Q9XFB2 & TC191581 & 9.42 & 0.013 \\
\hline 40 & TC192292_1560_39_S & Hippocampus abundant transcript 1 protein & B9SG70 & TC192292 & 14.79 & 0.0004 \\
\hline 41 & TC200857_1001_40_S & Ammonium transporter 1 member 1 & P58905 & TC200857 & 2.05 & 0.043 \\
\hline 42 & TC205660_580_35_S & Metal tolerance protein & B9GLJ8 & TC205660 & 3.77 & 0.049 \\
\hline 43 & TC206149_966_36_S & Aluminum-activated malate transporter 9 & Q9LS46 & TC206149 & 2.41 & 0.048 \\
\hline 44 & TC208376_922_36_S & Oligopeptide transporter, putative & B9SA63 & TC208376 & 17.67 & 0.004 \\
\hline 45 & TC215768_1111_35_X2 & Aquaporin & Q8W506 & TC215768 & -2.03 & 0.023 \\
\hline 46 & TC215874_553_40_S & Sec14 cytosolic factor, putative & B9S6A7 & TC215874 & 3.5 & 0.009 \\
\hline
\end{tabular}


Table 2 List of transcripts modulated in response to Fe-deficiency and reported in the Discussion (Continued)

\begin{tabular}{|c|c|c|c|c|c|c|}
\hline 4 & TC216882_1121_38_X2 & Hippocampus abundant transcript 1 protein & B9SG70 & TC216882 & 9.29 & 0.003 \\
\hline & \multicolumn{6}{|c|}{ Metabolic process GO:0008152; Carbon utilization GO:0015976 } \\
\hline 48 & TC204225_1412_35_S & Phosphoenolpyruvate carboxylase & P27154 & TC204225 & 3.31 & 0.039 \\
\hline \multirow[t]{2}{*}{49} & TC214978_700_36_S & Phosphoenolpyruvate carboxylase & P27154 & TC214978 & 3.74 & 0.036 \\
\hline & \multicolumn{6}{|c|}{ Metabolic process GO:0008152; Catabolic process GO:0009056 } \\
\hline 50 & TC194584_1854_37_S & Cysteine-type peptidase, putative & B9STX0 & TC194584 & 3.61 & 0.011 \\
\hline 51 & TC203350_1573_40_S & Vacuolar processing enzyme 1 & B2M1T0 & TC203350 & 2.18 & 0.026 \\
\hline 52 & TC208154_2059_38_S & Beta-amylase PCT-BMYI & Q94EU9 & TC208154 & -3.06 & 0.042 \\
\hline \multirow[t]{2}{*}{53} & TC215970_3405_40_S & Protease Do-like 7 & Q8RY22 & TC215970 & 4.01 & 0.032 \\
\hline & \multicolumn{6}{|c|}{ Metabolic process GO:0008152; Cellular metabolic process GO:0044237 } \\
\hline 54 & TC192049_1645_40_S & Sulfate adenylyltransferase & Q43183 & TC192049 & -2.48 & 0.029 \\
\hline 55 & TC193934_828_38_X2 & Methylthioribose kinase, putative & B9RY82 & TC193934 & 2.12 & 0.023 \\
\hline 56 & TC194380_182_36_S & S-adenosylmethionine-dependent methyltransferase, putative & B9SzS6 & TC194380 & 2.03 & 0.045 \\
\hline 57 & TC195032_699_35_S & CBL-interacting serine/threonine-protein kinase 11 & O22932 & TC195032 & -2.62 & 0.030 \\
\hline 58 & TC198109_708_34_X2 & Phosphofructokinase, putative & B9RRX6 & TC198109 & 2.00 & 0.036 \\
\hline 59 & TC199972_1164_40_S & Fructose-bisphosphate aldolase & Q2PYX3 & TC199972 & 2.53 & 0.022 \\
\hline 60 & TC201350_645_36_S & Protein phosphatase- $2 \mathrm{C}$ & 082469 & TC201350 & 2.10 & 0.028 \\
\hline 61 & TC201692_547_40_S & Xyloglucan endotransglucosylase/hydrolase 14 & B9RKL5 & TC201692 & 7.29 & 0.013 \\
\hline 62 & TC206357_361_38_S & Catalase isozyme 1 & P30264 & TC206357 & -2.79 & 0.046 \\
\hline 63 & TC212978_951_34_S & Phosphoenolpyruvate carboxylase & Q85915 & TC212978 & 3.62 & 0.030 \\
\hline 64 & TC214826_1684_35_S & ATP binding protein, putative & B9RII2 & TC214826 & 12.39 & 0.011 \\
\hline 65 & TC214837_697_40_S & Cytokinin oxidase/dehydrogenase & C3VPM8 & TC214837 & 4.64 & 0.015 \\
\hline 66 & TC216529_896_39_S & Peroxidase 7 & Q95Y33 & TC216529 & 9.25 & 0.011 \\
\hline \multirow[t]{2}{*}{67} & TC216572_542_40_S & Avr9/Cf-9 rapidly elicited protein 216 & Q84QE0 & TC216572 & -2.61 & 0.042 \\
\hline & \multicolumn{6}{|c|}{ Metabolic process GO:0008152; Oxidation reduction GO:0055114 } \\
\hline 68 & TC191412_2284_38_S & Ferric-chelate reductase & Q6EMCO & TC191412 & 15.21 & 0.008 \\
\hline 69 & TC191893_9_37_S & Superoxide dismutase & Q7YK44 & TC191893 & -2.29 & 0.030 \\
\hline 70 & TC194139_2083_38_S & Ferric-chelate reductase & B9RIU2 & TC194139 & -10.76 & 0.023 \\
\hline 71 & TC194227_76_41_X2 & Superoxide dismutase & Q7YK44 & TC194227 & -2.20 & 0.038 \\
\hline 72 & TC196465_645_40_X2 & Gibberellin 20 oxidase & B9RUX2 & TC196465 & 3.46 & 0.009 \\
\hline 73 & TC199400_1132_37_S & Peroxidase 2 , putative & B9SZA0 & TC199400 & -2.05 & 0.022 \\
\hline 74 & TC201832_1136_40_S & Gibberellin 20 oxidase & B9RUX2 & TC201832 & 3.00 & 0.013 \\
\hline 75 & TC205699_961_40_S & Chlorophyll synthase, putative & B9RJ38 & TC205699 & 7.12 & 0.019 \\
\hline 76 & TC207549_14_41_S & Cytochrome $\mathrm{C}$ oxidase polypeptide vib & B9RJN9 & TC207549 & 3.05 & 0.016 \\
\hline 77 & TC208767_662_38_S & Cationic peroxidase 1 & B9SWU3 & TC208767 & 4.75 & 0.022 \\
\hline \multirow[t]{2}{*}{78} & TC213071_429_40_S & Peroxidase & Q07446 & TC213071 & -3.29 & 0.032 \\
\hline & \multicolumn{6}{|c|}{ Metabolic process GO:0008152; Primary metabolic process GO:0044238 } \\
\hline 79 & TC197609_880_35_S & Zinc finger protein. putative & B9T6Q0 & TC197609 & 3.54 & 0.014 \\
\hline \multirow[t]{2}{*}{80} & TC192838_1967_36_S & Endo-1,4-beta-glucanase & B9RLZ9 & TC192838 & 2.45 & 0.042 \\
\hline & \multicolumn{6}{|c|}{ Metabolic process GO:0008152; Secondary metabolic process GO:0019748 } \\
\hline 81 & TC197109_626_37_S & Flavonoid 3-hydroxylase, putative & B9T1C6 & TC197109 & 2.56 & 0.024 \\
\hline 82 & TC198786_1057_37_S & UDP-glucose:glucosyltransferase & B6EWY6 & TC198786 & 2.19 & 0.022 \\
\hline 83 & TC203267_704_38_S & UDP-glucose:flavonoid glucoside 1,6-glucosyltransferase & C5NN14 & TC203267 & 2.76 & 0.013 \\
\hline \multirow[t]{2}{*}{84} & TC212095_566_35_S & UDP-glucose:flavonoid glucoside 1,6-glucosyltransferase & C5NN14 & TC212095 & 3.69 & 0.018 \\
\hline & \multicolumn{6}{|c|}{ Response to stimulus GO:0050896 } \\
\hline 85 & TC193192_66_41_X2 & Peroxidase 4 & B7UCP4 & TC193192 & -3.86 & 0.029 \\
\hline 86 & TC208216_282_40_S & Pit1 protein & Q40539 & TC208216 & 4.71 & 0.019 \\
\hline \multirow[t]{2}{*}{87} & TC195700_1019_40_S & Peroxidase & B9VRK9 & TC195700 & -2.67 & 0.013 \\
\hline & \multicolumn{6}{|l|}{ No hits found } \\
\hline 88 & TC203837_663_35_S & No hits found & & TC203837 & 2.06 & 0.046 \\
\hline 89 & TC204355_604_36_S & No hits found & & TC204355 & -3.09 & 0.038 \\
\hline 90 & TC207055_310_37_S & No hits found & & TC207055 & 3.05 & 0.03 \\
\hline
\end{tabular}


Table 2 List of transcripts modulated in response to Fe-deficiency and reported in the Discussion (Continued)

\begin{tabular}{llllll}
\hline 91 & TC209134_260_40_S & No hits found & TC209134 & 30.06 & 0.007 \\
92 & TC209988_335_40_S & No hits found & TC209988 & 6.82 & 0.013 \\
93 & TC211287_216_38_S & No hits found & TC211287 & 7.63 & 0.011 \\
94 & TC212074_241_40_S & No hits found & TC212074 & 6.44 & 0.023 \\
95 & TC212933_306_37_S & No hits found & TC212933 & 9.59 & 0.011 \\
96 & TC214074_254_40_S & No hits found & TC214074 & 2.22 & 0.041 \\
97 & TC215128_252_35_S & No hits found & TC215128 & 3.86 \\
\hline
\end{tabular}

aID of TomatoArray2.0 probes

${ }^{b}$ Description of each transcript. Bold discussed; italics undiscussed.

'UniProtID [26] of the first hit obtained by BlastP analysis

${ }^{d}$ ID of the TC of DFCI Tomato Gene Index (Release 12.0) [92]

e Fold change value

fadjusted $p$-value

MACROPHAGE PROTEIN1 (LeNRAMP1; \#38) [29,32]. A positive modulation of FER and Fe mobilization proteins (IRT1, NRAMP1 and FRO1) was not found in two proteomics studies performed in tomato roots grown in conditions similar to those used in the present work $[15,16]$. Authors justified these results as related to the features of proteomic approach, which was not sensitive enough to detect FER and not well suited for membrane-bound proteins. However, functional characterizations of fer mutant proved that FER controls the expression of the iron-uptake genes [29,32,33]. A transcriptional behaviour similar to that described in the present work was observed for Arabidopsis orthologous genes in Fe-starved roots $[5,8,11,34]$.

Our data show a strong down-regulation of another ferric chelate reductase (\#70). Previous results indicated that the same transcript (TC194139 of the Release 12.0, corresponding to TC124302 of the Release 9.0) specific to the Solanum lycopersicum genome, is only slightly regulated by Fe and that its function is not essential for Fe uptake [34]. Our results showing a negative regulation of this FRO transcript in response to Fe-deficiency in roots, also quantified by Real-time RT-PCR experiment, confirm that this gene does not play a crucial role in deficiency-induced Fe uptake and suggest the involvement in other biological process.

Together with the positive modulation of LeFER, LeFRO1 and LeIRT1, we observed for the first time a high up-regulation of another bHLH transcript (\#26); this result suggests that like in Arabidopsis [35] also in tomato plants the response to Fe deficiency through FER activity may need the interaction with another bHLH protein. BlastP analysis against TAIR database [36] using protein sequence obtained from the predicted coding sequence of the TC194645 showed the highest sequence homology with the protein encoded by AtbHLH38 (score: 120; Evalue: 9 E-28; identity: 35\%; positives: 57\%) known to interact with FIT, the Arabidopsis orthologous of tomato FER [35].

The down-regulation of two ferritin transcripts (\#25 and 30) is in line with the negative regulation of ferritin genes observed in roots of Fe-depleted Arabidopsis plants $[5,8,11]$. It has been suggested that ferritins can be involved in Fe homeostasis [37] with a main role of plastidial Fe [11]. Arabidopsis nodulin-like genes have been recently described to be putatively involved in Fe transport and storage under metal cation sufficiency [38]. Transcriptional levels of Arabidopsis nodulin-like genes were down-regulated at least until 72-h of Fe-deficiency, while two other nodulin-like genes were not modulated in response to different Fe conditions [38]. On the other hand in tomato roots we recorded a positive modulation of two transcripts encoding protein with a nodulin-like domain (\#9 and 22). BlastP analysis against TAIR database [36] using protein sequence obtained from the predicted coding sequence of the

Table 3 Real-time RT-PCR validation of a set of genes differentially expressed in microarray analysis

\begin{tabular}{llll}
\hline TC ID & Description & Real-time RT-PCR (ratio) & Microarray \\
\hline TC208376 & Oligopeptide transporter, putative & $17.87 \pm 4.35$ & 17.67 \\
\hline NP796451 & Root-specific metal transporter & $15.11 \pm 3.97$ & 12.00 \\
\hline TC191581 & Iron-regulated transporter 1 & $3.07 \pm 0.59$ & 9.42 \\
\hline TC216882 & $\begin{array}{l}\text { Hippocampus abundant transcript 1 } \\
\text { protein, putative }\end{array}$ & $8.69 \pm 1.53$ & 9.29 \\
\hline TC205660 & Metal tolerance protein & $1.55 \pm 0.44$ & 3.77 \\
\hline TC194139 & Ferric-chelate reductase, putative & $-12.14 \pm 3.15$ & -10.76 \\
\hline
\end{tabular}


TC214599 (\#22) showed the highest sequence homology with the protein encoded by At3g43660 (score: 325; Evalue: 2 E-29; identity: 54\%; positives: $68 \%$ ) which is one of the two Arabidopsis genes not modulated by iron [38].

\section{Metabolic processes \\ Carbohydrate metabolism}

As observed in Arabidopsis root microarray analyses $[5,8,11]$ glycolysis-related genes are positively modulated in Fe-deficient roots. These transcriptional data fit well with the increased activity of glyceraldehyde-3-phosphate dehydrogenase (GADPH), pyruvate kinase (PK), and phosphofructokinase (PFK) recorded in response to Fe starvation in cucumber roots [39]. Furthermore, increased levels of protein related to glycolysis under Fe shortage were recently reported in sugar beat [17] and Medicago truncatula [20] roots. All together these evidences are consistent with the idea of a shift from anabolic to catabolic metabolism. In the present work, a fructose-bisphosphate aldolase (FBP aldolase) (\#59) and a PFK (\#58) transcripts were up-regulated under Fe deficiency, further confirming changes in primary metabolism in response to Fe starvation. The positive modulation of transcript encoding a PFK, an enzyme catalysing a protogenic reaction, supports the role of glycolysis in different process such as production of ATP and $\mathrm{H}^{+}$for $\mathrm{H}^{+}$-ATPase, reducing equivalents for ferric chelate reductase and of phosphoenolpyruvate (PEP) [40]. Up-regulation of three phosphoenolpyruvate carboxylase (PEPC) transcripts (\#48, 49 and 63) agrees with results of several proteomic and physiological studies on the response to Fe deficiency in tomato $[15,16,41]$, sugar beat [17] and Medicago truncatula roots [20], showing a positive modulation of proteins involved both in glycolysis and TCA cycle. PEPC activity, through pyruvate consumption, can keep active the glycolytic pathway and give a contribution to the control of cytosolic pH $[40,41]$. In Fe deficiency, starch catabolism was reported to be enhanced both at transcriptional [5] and protein level [16]. Our analysis revealed a down-regulation of a transcript encoding a protein showing homology to a potato chloroplastic ßamylase (\#52) involved into starch degradation in plastids [42]. Since starch catabolism mediated by this enzyme occurs in plastids, the negative modulation of $ß$-amylase could be ascribed to other causes than an accelerated glycolysis.

The positive modulation of a cytochrome $\mathrm{C}$ oxidase (\#76) is in line with the transient induction of electrontransport-chain genes observed in Arabidopsis [5] and consistent with the enhancement of respiration rate observed in cumber [39] and sugar beat [43] Fe-deficient roots. This behaviour was interpreted as an attempt to increase energy production through oxidative phosphorylation. However, more recently it has been suggested that the increased respiration rate in root segments of Fe-starved cucumber plants should not be interpreted as an increase in mitochondrial activity but rather as the result of an increase in the number of less efficient mitochondria and of the induction of different $\mathrm{O}_{2}$-consuming reaction [44].

\section{Methionine cycle}

Nicotianamine (NA) is considered to be a key molecule for long-distance transport of Fe in plants [45]. Proteomic analysis of Fe-starved tomato roots [16] showed a positive modulation of proteins related to metabolism of methionine (e.g. methionine synthase), a precursor of nicotianamine. An up-regulation of a transcript encoding a methylthioribose kinase (MTK, \#55), another enzyme of the methionine cycle, was observed in our transcriptional analysis. A positive modulation of MTK transcripts was also recorded in roots of rice, a Strategy II plant species, under Fe deficiency [46,47], although in this case, related to the necessity to increase the production of mugineic acid.

A down-regulation of a sulfate adenylyltransferase (ATPS; ATP sulfurylase) gene (\#54) was observed in this work. However, the opposite was found in Arabidopsis [11]. The connection between the sulphur nutritional status and capability to respond to Fe shortage has been demonstrated in both Strategy I and Strategy II plants $[30,48]$. Recently an increase in methionine content related to phytosiderophore synthesis without significant changes in ATPS activity was described in Fe-deficient barley roots [48]. Interestingly, in a recent study of Medicago truncatula root proteome [20] two enzymes related to biosynthesis of cysteine and methionine were negatively affected by Fe deficiency.

\section{Protein turnover}

Response to Fe starvation induced the accumulation of gene transcripts related to protein turn-over, including protease (\#53) and peptidase (\#50 and 51) involved in protein degradation, and a gene encoding a heterogeneous nuclear ribonucleoprotein (\#28) that can act in the pre-mRNA metabolism preceding protein synthesis.

The activity of these genes can be related to molecular events controlling plant responses to abiotic stresses such as nutritional deficiencies [49]. A general increase in protein synthesis was reported as a response to $\mathrm{Fe}$ deficiency in cucumber roots [50]; furthermore, protein recycling in response to Fe starvation was suggested by analysis of expression profiles of soybean [13] and proteomic changes in cucumber [18] and Medicago troncatula [20] roots. Transcriptomic data presented here are in line with the idea that, under Fe deficiency, $\mathrm{N}$ recycling reactions take place, possibly related to the necessity of additional anaplerotic source of $C$ and $N[18,20]$. 


\section{Secondary metabolism}

Phenolic compounds are reported as components of root exudates in Fe-deficient Strategy I plants. These molecules are involved in chelation and/or reduction of rhizospheric insoluble Fe [51,52]. Recently, phenolics have been proposed to selectively influence rhizospheric microorganisms and be involved in the reutilization of apoplastic Fe [53]. Our results showed an up-regulation of a flavonoid-3-hydroxylase (\#81) gene and of three genes putatively involved into flavonoid glycosylation (\#82, 83 and 84). Two out of the last three genes showed sequence homology to a Catharanthus roseus flavonoid glucoside 1,6-glucosyltransferase catalysing 1,6-glucosylation of flavonol and flavone glucosides [54]. A positive modulation of genes related to general phenylpropanoid pathway (e.g. genes encoding PAL and 4CL) was reported in Fe-deficient Arabidopsis roots [11]. Data of the present work underline the up-regulation of transcripts involved in a more specific branch of phenolic pathway supporting the idea that Fe-starved roots might operate flavonoid secretion into the rhizosphere in order to promote Fe acquisition [55].

\section{Oxidative stress responses}

Many proteins involved in antioxidative defence response contain $\mathrm{Fe}$ in heme group or coordinated to the thiol group of cysteine. The modulation of transcripts and proteins related to oxidative stress response in roots of Fe-starved plants seems to depend on the species and the experimental conditions $[5,13,17,19]$. However, catalase (CAT) and peroxidase (POX) activities are known to be depressed under Fe deficiency conditions [56] in tomato leaves. Our data showed a main down-regulation of transcripts encoding thioredoxin (TRX) (\#29) and detoxifying enzymes catalase (CAT; \#62), superoxide dismutase (\#69 and 71), peroxidase (POX; \#73, 78, 85 and 87). Two other POX transcripts (\#66 and 77) and a thioredoxin peroxidase gene (\#27) were, conversely, up-regulated. At protein level, a decrease of a CAT was reported while some POXs showed higher levels in response to Fe deficiency in tomato roots [15]; a different response of peroxidase isoforms has also been reported in sunflower [57]. Taken together, data of the present work suggest a different role in response to nutrient stress condition between the thioredoxin $(\mathrm{ABB})$ and POX isogenes and are in agreement with previous results obtained in Medicago truncatula [20] and sugar beat [17] Fe-deficient roots.

A germin-like transcript (\#15) was up-regulated under Fe deficiency, similarly to what has been observed in the tomato root proteome analysis [15]. The positive modulation of a germin protein reported in this proteomic study was justified hypothesizing its role in producing hydrogen peroxide for apoplastic Fe reduction or in other stress response on the basis of sequence similarity to a Nicotiana attenuata germin protein $[15,58]$.

\section{Root morphological adaptation}

Morphological modifications in roots of Fe-deficient plants are well documented $[59,60]$. Root hairs proliferation and development of transfer cells were described in Fe-starved tomato plants [29,61-63]. Enhanced formation of lateral roots and root hairs was also recorded in our experiment (Figure 1). Extensin proteins seem to be involved in this latter phenomenon; in fact, we observed a strong positive modulation of LeExt1 (\#32, 33 and 35), LeDif10 (\#36) and LeDif54 (\#31 and 34). It was reported that these three genes encode extensin, a structural protein putatively conferring physical characteristics of the cell wall [64], and act during root hair formation in tomato due their predominant expression in root hair cells $[64,65]$.

The overexpression of an endo-1,4- $\beta$-glucanase (\#80) and a xyloglucan endotransglucosylase/hydrolase protein (\#61) transcripts could be involved into the cell wall loosening [66] associated to root morphological adaptation to Fe deficiency, as previously observed in a tomato root proteomic analysis [16]. These changes in root morphology are also supported by the up-regulation of a transcript showing homology to a tobacco actin-depolymerizing factor (\#37) related to the pollen tube elongation [67]. Here, we report a negative modulation of a transcript (\#45) showing homology to the tobacco aquaporin PIP2 [68] suggesting a role of the PIP2 tomato protein in Fe-related morphological root changes. It has been suggested that PIP aquaporins can play a role not only in root water uptake but also in root development [68]. Transgenic plants exhibiting RNAi of PIP2 aquaporins showed a significant increase in the length of primary roots [68].

\section{Transport processes}

Among the positively modulated transcripts belonging to "transport" functional category, a stronger modulation (more than 17 times) of an oligopeptide transporter (OTP) gene (\#44) was observed under Fe shortage. BlastP analysis against TAIR database [36] using protein sequence obtained from the predicted coding sequence of the TC208376 (\#44) showed the highest sequence homology with the protein encoded by AtOPT3 (score: 541; Evalue: E-154; identity: 83\%; positives: 90\%). Positive modulation of AtOPT2 and AtOPT3 has been recorded in Fe-deficient Arabidopsis roots [8,11,21,69]. The plant members of OTP family have been described to have different functions in transport physiology such as long-distance sulphur distribution, nitrogen 
mobilization, metal homeostasis, and heavy metal sequestration. OPTs can transport glutathione, metalchelates and peptides [70]. It was hypothesized that some plants OTPs are able to transport Fe-chelates and Fe-NA suggesting a role of these proteins in long-distance metal transport in planta [71,72]. A similar function can be hypothesized for the tomato up-regulated OPT transcript, due to the previously described positive modulation of genes related to NA synthesis (see methionine cycle paragraph).

Another up-regulated gene involved in transport phenomena in response to Fe-deficiency is LeAMT1 (\#41). This tomato gene, firstly isolated from a root hair cDNA library [73] was root-specifically expressed and positively regulated by ammonium $\left(\mathrm{NH}_{4}{ }^{+}\right)$in root hairs $[73,74]$. This result suggests the presence of a linkage between $\mathrm{NH}_{4}{ }^{+}$uptake and Fe shortage. It has been demonstrated that $\mathrm{NH}_{4}{ }^{+}$-dependent rhizosphere acidification can improve Fe availability in the rhizosphere [75]. Interestingly, nitrate acquisition is limited under Fe deficiency $[20,76]$.

Furthermore, favouring ammonium uptake with respect to nitrate could reduce competition for reducing equivalent between nitrogen and Fe acquisition. This is also in agreement with the hypothesized $\mathrm{N}$-recycling in Fe-deficient plant roots [20].

Fe-deficient tomato roots strongly overexpressed two transcripts (\#40 and 47) encoding a protein sharing features of major facilitator superfamily (MSF) with putative transport activities. However, on the basis of their sequence homology it was not possible to hypothesize an involvement in transport of a specific metabolite or mineral nutrient.

A positive modulation of a gene encoding a metal tolerance protein (MTP; \#42) was also recorded. A similar behaviour was described in Fe-deficient Arabidopsis roots $[8,11]$ and interpreted in the light of low specificity of IRT1 transporters, which can transport different metals into the Fe-deficient plants. MTP genes might therefore play a role in the detoxification of zinc ions taken up absorbed under Fe deficiency conditions [11].

Fe deficiency in tomato induced the expression of a transcript (\#43) encoding a protein showing sequence homology to Arabidopsis vacuolar aluminium-activated malate transporter (ALMT) 9 [77]. An increase in organic acids concentration mainly citric and malic acids in plant roots under Fe starvation has been reported for many plant species [78]. However, a decrease of malate levels was observed in tomato root tips after 15-d of Fe deficiency while higher contents were recorded in leaves and xylem sap [41]. The tomato malate transporter gene might be involved in malate fluxes at intracellular level and/or in long-distance transport in planta.

\section{Hormone metabolism and signaling}

The role of plant hormones in the regulation of Fe deficiency responses has been extensively studied $[79,80]$. As for Arabidopsis Col-0 accession, we identified the positive modulation of a methionine cycle gene, MTK gene, that could be related not only to NA synthesis (see above) but also to the recycling of methylthioadenosine during ethylene production [11]. This is in agreement with the hypothesized involvement of ethylene and/or auxin in control of hair root production under Fe deficiency [79]. Furthermore, data of the present work suggest the involvement of other hormones (such as gibberellin and cytokinin) in Fe deficiency response in tomato roots. Concerning gibberellin, we recorded the up-regulation of two gibberellin oxidase 20 (GA20OX) transcripts (\#72 and 74). They can regulate root morphological changes through the synthesis of active GA1. Indeed, it has been reported that GAs are related to tomato root growth [81]. In addition, it was shown that the expression of a tomato SlGA20ox1:GUS construct in Arabidopsis localized also in columella of secondary roots [82], thus suggesting a role in secondary root formation. The same authors also reported that the expression of the construct was positively affected in cotyledons, hypocotyls and roots by benziladenine, a synthetic cytokinin [82]. However cytokinins were described as negative regulators of root Fe uptake mechanism in Arabidopsis through a root-growth dependent pathway [83]. Cytokinins could play a similar role also in tomato roots. This hypothesis is supported by the up-regulation of a cytokinin oxidase/dehydrogenase (CKX) gene (\#65) under Fe starvation. CKX genes are involved in regulation of plant growth and development through the control of the cytokinin concentration [84].

Focusing on signal transduction, we observed the upregulation of a transcript (\#60) encoding a protein with sequence homology to the MCP5, a protein phosphatase-2C (PP2C) of Mesembryanthemum crystallinum [85]. McMCP5 is expressed in roots and is induced in response to salt and drought stresses [85]. The tomato PP2C gene could play a role in signal transduction of stress nutrient condition as Fe starvation. The positive modulation of a gene encoding a SRC2 protein containing a $\mathrm{C} 2$ domain (\#1) suggests a putative involvement of $\mathrm{Ca}$ as secondary messenger. Focusing on $\mathrm{Ca}$, in our experiment we also identified a down-regulated gene (\#57) in Fe-starved roots showing homology to an Arabidopsis gene (AtSOS2) encoding a CBL-interacting serine/threonine-protein kinase 11. Arabidopsis SOS2 interacts with the Ca binding protein SOS3 (SALT OVERLY SENSITIVE 3), thus controlling $\mathrm{K}$ and $\mathrm{Na}$ homeostasis and the response to salt stress [86,87]. In addition a negative modulation of a gene (\#67) showing 
homology to a tobacco Avr/Cf-9 rapidly elicited (ACRE) transcript encoding a PP2C was observed [88]. Our data confirm the results obtained with proteome analysis of tomato roots in response to Fe-deficiency, where changes in the levels of proteins involved in signal transduction were reported [16]. The observed transcriptional changes in tomato roots can be the result of the perception of nutrient stress condition and the following signal transduction.

Taken together, these results suggest that Fe deficiency responses are, at least in part, dependent on hormonal balance modifications possibly resulting from signal perception and transduction.

\section{Conclusion}

Ninety-seven differentially expressed transcripts were identified comparing root transcriptional profiles of Fedeficient and Fe-sufficient tomato plants. Tomato roots respond to Fe deficiency by modulating the expression of a number of transcripts similar to the model plant Arabidopsis. The comparison of tomato Fe-responsive transcript set with the Arabidopsis "ferrome" [21], encompassing 92 transcripts that robustly represent the response to Fe shortage, confirms the involvement of the well know homologous key regulatory elements (e.g. bHLHs) controlling the expression of transcripts related to Fe uptake and translocation (e.g. IRT and FRO). As showed by Arabidopsis "ferrome" [21], tomato roots modulate transcripts involved in homeostasis of Fe and heavy metal cations (e.g. IRT, NRAMP, MTP, ferritin) and others cation (e.g. AMT). Both plant species require the up-regulation of transcripts related to glycolysis (e.g. PFK) and methionine cycle (e.g. MTK), the latter pathway being putatively linked to NA biosynthesis in response to Fe deficiency. Fe-NA complexes could be transported both in tomato and Arabidopsis plants through OPTs during the response to Fe shortage. Here we describe, for the first time, the modulation of a specific branch of phenolic (flavonoids) biosynthesis in response to Fe deficiency. In addition, tomato roots seem to be more characterized by root morphological adaptation, mainly linked to hair root production, as suggested by the strong up-regulation of extensin transcripts.

Therefore, this transcriptional study, while confirming evidence coming from proteomic studies, allowed identifying new putative targets for further functional investigations on the response to Fe deficiency in tomato roots.

\section{Methods}

Plant material, growth conditions and RNA extractions

Tomato seedling (Solanum lycopersicum L., cv. 'Marmande superprecoce' from DOTTO Spa, Italy), germinated for 6 days on filter paper moistened with 1 $\mathrm{mM} \mathrm{CaSO}_{4}$, were grown for 14 days in a continuously aerated nutrient solution ( $\mathrm{pH}$ adjusted at 6.0 with $1 \mathrm{M}$ $\mathrm{KOH})$ as reported by Tomasi at al. [22] with $5 \mu \mathrm{M} \mathrm{Fe}$ (Fe-EDTA); thereafter, most of the plants were transferred for a further week to a Fe-free nutrient solution (Fe-deficient) and some tomato plants were transferred for a week to a nutrient solution containing $100 \mu \mathrm{M} \mathrm{Fe-}$ EDTA (Fe-sufficient plants) as control. Nutrient solutions were renewed every three days. The controlled climatic conditions were the following: day/night photoperiod, $16 / 8 \mathrm{~h}$; light intensity, $220 \mu \mathrm{E} \mathrm{m}^{-2} \mathrm{~s}^{-1}$; temperature (day/night) $25 / 20^{\circ} \mathrm{C}$; RH 70 to $80 \%$.

At the end of the growing period (27 days), Fe-deficient tomato plants clearly showed visible symptoms of Fe deficiency yellowing of the fully expanded apical leaves and proliferation of lateral roots and root hairs and increase in the diameter of the sub-apical root zone. 24 hours before harvesting, all nutrient solutions (both for Fe-deficient and Fe-sufficient plants) were renewed and the $\mathrm{pH}$ was adjusted to 7.5 with $10 \mathrm{mM}$ Hepes$\mathrm{KOH}$. The $\mathrm{pH}$ of the growing medium was adjusted to this value to mimic as close as possible the conditions that are occurring in Fe-deficiency-inducing soil. However, in order to favour an equilibrate development of tomato plants growing in the Fe-free nutrient solution, the exposure to the $\mathrm{pH}$ of 7.5 was limited to the last two days.

Roots of Fe-deficient and Fe-sufficient tomato plants (27 d-old) were harvested five hours after the beginning of light phase. The collected roots were immediately frozen in liquid nitrogen and stored until further processing at $-80^{\circ} \mathrm{C}$. The collection was repeated in three independent cultivations and the roots from six plants were pooled for each treatment.

\section{Ferric-chelate reduction}

To determine the root capacity to reduce Fe(III)-EDTA, accordingly to Pinton et al. [89] roots of a single intact (Fe-sufficient or Fe-deficient) tomato plants were incubated in the dark at $25^{\circ} \mathrm{C}$ for $60 \mathrm{~min}$ in $50 \mathrm{~mL}$ of an aerated solution containing $\mathrm{CaSO}_{4} 0.5 \mathrm{mM}$, BPDS 0.5 $\mathrm{mM}$, Hepes- $\mathrm{KOH} 10 \mathrm{mM}$ (pH 5.5) and $0.25 \mathrm{mM}$ of $\mathrm{Fe}$ (III)-EDTA. Thereafter, the absorbance of the solutions at $535 \mathrm{~nm}$ was measured at intervals of $15 \mathrm{~min}$ and the amount of $\mathrm{Fe}(\mathrm{III})$ reduced calculated by the concentration of the $\mathrm{Fe}(\mathrm{II})-\mathrm{BPDS}_{3}$ complex formed, using an extinction coefficient of $22.1 \mathrm{mM}^{-1} \mathrm{~cm}^{-1}$.

\section{Microarray analysis}

Transcriptional analysis was carried out using a Combimatrix [24], produced by the Plant Functional Genomics Center, University of Verona [90]. The chip (TomatoArray2.0) carries 25,789 nonredundant probes $(23,282$ 
unique probes and 2,507 probes with more than one target) randomly distributed in triplicate across the array, each comprising a 35-40-mer oligonucleotide designed using the program oligoarray 2.1 [91]. The source of sequence information included tentative consensus sequences (TCs) derived from the DFCI Tomato Gene Index [92] Release 12.0 and expressed sequence tags. Eight bacterial oligonucleotide sequences provided by CombiMatrix, 8 probes designed on 8 Ambion spikes and 40 probes based on Bacillus anthracis, Haemophilus ducreyi and Alteromonas phage sequences were used as negative controls. Complete description of chip is available at the Gene Expression Omnibus [93] under the series entry (GPL13934).

Total RNA was isolated using the Spectrum ${ }^{\mathrm{TM}}$ Plant Total RNA kit (Sigma-Aldrich) and quantified by spectrophotometry using NanoDrop ${ }^{\mathrm{TM}} 1000$ Tem Scientific). RNA quality was evaluated using Agilent 2100 Bioanalyzer (Agilent). Total RNA (1 $\mu \mathrm{g})$ was amplified and labelled using the RNA ampULSe kit (Kreatech). After checking the quantity and quality of aRNA by spectrophotometry using NanoDrop ${ }^{\mathrm{TM}} 1000$ (Thermo Scientific) and the quality subsequent labelling, $4 \mu \mathrm{g}$ of labelled aRNA was hybridized to the array according to the manufacturer's recommendations [24]. Pre-hybridization, hybridization, washing and imaging were performed according to the manufacture's protocols. The array was scanned with an Axon GenePix ${ }^{\mathbb{B}}$ 4400A scanner (MDS Analytical Technologies).

Analysis of raw data was performed using the open source software of the Bioconductor project $[94,95]$ with the statistical R programming language [96,97]. Background adjustment, summarization and quantile normalization were performed using limma package [25]. Differentially expressed probes were identified by linear models analysis [25] using limma package and applying Bayesian correction, adjusted p-value of 0.05 and a $|F C|$ $\geq 2$. All microarray expression data are available at the Gene Expression Omnibus [93] under the series entry (GSE31112). Genes were grouped in main functional categories according to the "biological" terms of the Gene Ontology [27] assigned to each tomato TC or EST (Release 12.0) on the basis of the results of BlastP analysis [98] against the UniProt database [26] (Additional file 1). Genes without significant BlastP results were classified as "no hits found" (Evalue $<1$ e-8; identity $>40 \%$ ).

\section{Real-time RT-PCR experiments}

$0.5 \mu \mathrm{g}$ of total RNA (checked for quality and quantity using a spectrophotometer NanoDrop ${ }^{\mathrm{TM}} 1000$ (Thermo Scientific), followed by a migration in an agarose gel) of each sample was retrotranscribed using 1 pmol of Oligo $\mathrm{d}(\mathrm{T}) 23 \mathrm{VN}$ (New England Biolabs, Beverly, USA) and 10 $\mathrm{U}$ M-MulV RNase $\mathrm{H}$ for $1 \mathrm{~h}$ at $42^{\circ} \mathrm{C}$ (Finnzymes,
Helsinki, Finland) following the application protocol of the manufacturers. After RNA digestion with $1 \mathrm{U}$ RNase A (USB, Cleveland, USA) for $1 \mathrm{~h}$ at $37^{\circ} \mathrm{C}$, gene expression analyses were performed by adding $0.16 \mu \mathrm{l}$ of the cDNA to the realtime PCR complete mix, FluoCycleTM sybr green (20 $\mu \mathrm{l}$ final volume; Euroclone, Pero, Italy), in a DNA Engine Opticon Real-Time PCR Detection (Biorad, Hercules, USA). Specific primers $\left(\mathrm{Tm}=58^{\circ} \mathrm{C}\right)$ were designed to generate $80-140 \mathrm{bp}$ PCR products (Additional file 2). Three genes were used as housekeeping to normalized the data: elongation factor 1-alpha EF1a (X14449; TC203463; forward: 5'- TGGATATGCTCCAGTGCTTG-3'; reverse: 5'TTCCTTACCTGAACGCCTGT-3'), histone H1 (AJ224933; TC192148; forward: 5'- CAAAGGCCAAAACTGCTACC-3'; reverse: 5'-AGGCTTTACAGCTGCTTTCG-3') and ubiquitin Ubi3 (X58253; TC196208; forward: 5'-AGCCAAAGAAGATCAAGCACA-3'; reverse: 5'-GCCTCTGAACCTTTCCAGTG3'). Each Real-Time RT-PCR was performed 4 times on 3 independent experiments; analyses of real-time result were performed using Opticon Monitor 2 software (Biorad, Hercules, USA) and R [93] with the qpcR package [99]. Efficiencies of amplification were calculated following the authors' indications [100]: PCR efficiencies were $99.15 \%, 89.16 \%$ and $87.25 \%$, for EF1a, H1 and Ubi3 genes, respectively. The efficiencies for TC191581, TC192292, TC194139, TC216882, TC205660, TC208376 and NP796451 were respectively 94.75, 85.03, 98.92, 91.55, 92.70, 96.61 and $92.43 \%$. The reported Real time data were normalized on the EF1a gene. Gene expression data were illustrated considering the differences in the amplification efficiency of PCR and using the gene expression levels in roots of Fe-sufficient plants as reference; applying the following formula:

$$
\text { gene exp ression } \quad x_{-F e}=\frac{\left(2 \times E_{x}\right)^{\left[c_{t}(x+F e)-c_{t}(x-F e)\right]}}{\left(2 \times E_{\gamma}\right)^{\left[c_{t}(y+F e)-c_{t}(y-F e)\right]}}
$$

Where: $E_{x \text { or } y}$ is the percentage value of PCR efficiency for the amplification of the gene $\mathrm{x}$ or $\mathrm{y}$, respectively; $\mathrm{C}_{\mathrm{t}}\left(\mathrm{x}_{+\mathrm{Fe}}\right) \mathrm{Ct}$ for the control treatment $(+\mathrm{Fe})$ and the considered gene $(\mathrm{x}) ; C_{t}\left(\mathrm{x}_{-\mathrm{Fe}}\right)$; $\mathrm{Ct}$ for the treated roots $(-\mathrm{Fe})$ and the considered gene $(\mathrm{x}) ; C_{t}\left(\mathrm{y}_{+\mathrm{Fe}}\right) \mathrm{Ct}$ for the control treatment $(+\mathrm{Fe})$ and the housekeeping gene $(\mathrm{y})$; $C_{t}\left(\mathrm{y}_{-\mathrm{Fe}}\right) \mathrm{Ct}$ for the treated roots $(-\mathrm{Fe})$ and the housekeeping gene $(\mathrm{y})$.

\section{Additional material}

Additional file 1: Functional annotation of 97 differentially

expressed transcripts. ProbelD. Fold change. adjusted p-value. reference Tentative Consensus sequence in DFCI Tomato Gene Index (Release 12.0) http://compbio.dfci.harvard.edu/cgi-bin/tgi/gimain.pl?gudb=tomato. 
description. UniProtID http://www.uniprot.org/. Biological process GO term and E-value are reported for each probe.

Additional file 2: Primer sequences of Real-time RT-PCR experiment $T C I D$, description and sequences of forward and reverse primers are reported.

\section{Acknowledgements}

This work was supported by grants: MIUR (FIRB-Futuro in Ricerca and PRIN), Cariverona and Internal Projects UniBZ

\section{Author details}

${ }^{1}$ Department of Biotechnology, University of Verona, via delle Grazie 15 37134 Verona, Italy. ${ }^{2}$ Department of Agriculture and Environmental Sciences, University of Udine, via delle Scienze 208, 33100 Udine, Italy. ${ }^{3}$ Faculty of Science and Technology, Free University of Bolzano, piazza Università 5, 39100 Bolzano, Italy.

\section{Authors' contributions}

AZ and LZ made a substantial contribution to data collection and interpretation and manuscript drafting. NT participated in the project's design, data analysis and manuscript revision. MP critically revised the manuscript. RP contributed to data interpretation and critically revised the manuscript. ZV contributed to data interpretation and manuscript writing. SC participated in the project's design and coordination and critically revised the manuscript. All authors read and approved the final manuscript.

\section{Competing interests}

The authors declare that they have no competing interests.

Received: 3 August 2011 Accepted: 20 March 2012

Published: 20 March 2012

\section{References}

1. Hansen NC, Hopkins BG, Ellsworth JW, Jolley VD: Iron nutrition in field crops. In Iron nutrition in plants and rhizospheric microorganisms.. 1 edition Edited by: Barton LL, Abadia J. Dordrecht: Springer; 2007:23-59.

2. Hansch $R$, Mendel RR: Physiological functions of mineral micronutrients (Cu, Zn, Mn, Fe, Ni, Mo, B, Cl). Curr Opin Plant Biol 2009, 12:259-266.

3. Marschner $H$, Romheld $V$, Kissel M: Different strategies in higher plants in mobilization and uptake of iron. J Plant Nutr 1986, 9:695-713.

4. Ivanov R, Brumbarova T, Bauer P: Fitting into the Harsh Reality: Regulation of Iron-deficiency Responses in Dicotyledonous Plants. Mol Plant 2012, 5:27-42.

5. Thimm O, Essigmann B, Kloska S, Altmann T, Buckhout TJ: Response of Arabidopsis to iron deficiency stress as revealed by microarray analysis. Plant Physiol 2001, 127:1030-1043.

6. Colangelo EP, Guerinot ML: The essential basic helix-loop-helix protein FIT1 is required for the iron deficiency response. Plant Cell 2004, 16:3400-3412.

7. Dinneny JR, Long TA, Wang JY, Jung JW, Mace D, Pointer S, Barron C, Brady SM, Schiefelbein J, Benfey PN: Cell identity mediates the response of Arabidopsis roots to abiotic stress. Science 2008, 320:942-945.

8. Buckhout TJ, Yang TJ, Schmidt W: Early iron-deficiency-induced transcriptional changes in Arabidopsis roots as revealed by microarray analyses. BMC Genomics 2009, 10:147

9. Forner-Giner MA, Llosá MJ, Carrasco JL, Pérez-Amador MA, Navarro L, Ancillo G: Differential gene expression analysis provides new insights into the molecular basis of iron deficiency stress response in the citrus rootstock Poncirus trifoliata (L.) Raf. J Exp Bot 2010, 61:483-490.

10. García MJ, Lucena C, Romera FJ, Alcántara E, Pérez-Vicente R: Ethylene and nitric oxide involvement in the up-regulation of key genes related to iron acquisition and homeostasis in Arabidopsis. J Exp Bot 2010, 61:3885-3899.

11. Yang TJ, Lin WD, Schmidt W: Transcriptional profiling of the Arabidopsis iron deficiency response reveals conserved transition metal homeostasis networks. Plant Physiol 2010, 152:2130-2141
12. O'Rourke JA, Graham MA, Vodkin L, Gonzalez DO, Cianzio SR, Shoemaker RC: Recovering from iron deficiency chlorosis in near-isogenic soybeans: a microarray study. Plant Physiol Biochem 2007, 45:287-292.

13. O'Rourke JA, Charlson DV, Gonzalez DO, Vodkin LO, Graham MA, Cianzio SR, Grusak MA, Shoemaker RC: Microarray analysis of iron deficiency chlorosis in near-isogenic soybean lines. BMC Genomics 2007, 8:476.

14. O'Rourke JA, Nelson RT, Grant D, Schmutz J, Grimwood J, Cannon S, Vance CP, Graham MA, Shoemaker RC: Integrating microarray analysis and the soybean genome to understand the soybeans iron deficiency response. BMC Genomics 2009, 10:376.

15. Brumbarova T, Matros A, Mock HP, Bauer P: A proteomic study showing differential regulation of stress, redox regulation and peroxidase proteins by iron supply and the transcription factor FER. Plant J 2008, 54:321-334.

16. Li J, Wu XD, Hao ST, Wang XJ, Ling HQ: Proteomic response to iron deficiency in tomato root. Proteomics 2008, 8:2299-2311.

17. Rellán-Alvarez R, Andaluz S, Rodríguez-Celma J, Wohlgemuth G, Zocchi G, Alvarez-Fernández A, Fiehn O, López-Millán AF, Abadía J: Changes in the proteomic and metabolic profiles of Beta vulgaris root tips in response to iron deficiency and resupply. BMC Plant Biol 2010, 10:120.

18. Donnini S, Prinsi B, Negri AS, Vigani G, Espen L, Zocchi G: Proteomic characterization of iron deficiency responses in Cucumis sativus L. roots. BMC Plant Biol 2010, 10:268.

19. Lan P, Li W, Wen TN, Shiau JY, Wu YC, Lin W, Schmidt W: iTRAQ protein profile analysis of Arabidopsis roots reveals new aspects critical for iron homeostasis. Plant Physiol 2011, 155:821-834.

20. Rodríguez-Celma J, Lattanzio G, Grusak MA, Abadía A, Abadía J, López Millán AF: Root responses of Medicago truncatula plants grown in two different iron deficiency conditions: changes in root protein profile and riboflavin biosynthesis. J Proteome Res 2011, 10:2590-2601.

21. Schmidt W, Buckhout TJ: A hitchhiker's guide to the Arabidopsis ferrome. Plant Physiol Biochem 2011, 49:462-470.

22. Tomasi N, Rizzardo C, Monte R, Gottardi S, Jelali N, Terzano R, Vekemans B, De Nobili M, Varanini Z, Pinton R, Cesco S: Micro-analytical, physiological and molecular aspects of Fe acquisition in leaves of Fe-deficient tomato plants re-supplied with natural Fe-complexes in nutrient solution. Plant Soil 2009, 325:25-38.

23. Zouari M, Abadía A, Abadía J: Iron is required for the induction of root ferric chelate reductase activity in iron-deficient tomato. J Plant Nutr 2001, 24:383-396.

24. CombiMatrix Diagnostics. [http://www.combimatrix.com].

25. Smyth GK: Linear models and empirical Bayes methods for assessing differential expression in microarray experiments. Stat Appl Genet Mol Biol 2004, 3, Article 3.

26. The UniProt Database. [http://www.uniprot.org/].

27. The Gene Ontology. [http://www.geneontology.org].

28. Eckhardt U, Mas Marques A, Buckhout TJ: Two iron-regulated cation transporters from tomato complement metal uptake-deficient yeast mutants. Plant Mol Biol 2001, 45:437-448.

29. Bereczky Z, Wang HY, Schubert V, Ganal M, Bauer P: Differential regulation of nramp and irt metal transporter genes in wild type and iron uptake mutants of tomato. J Biol Chem 2003, 278:24697-24704.

30. Zuchi S, Cesco S, Varanini Z, Pinton R, Astolfi S: Sulphur deprivation limits Fe-deficiency responses in tomato plants. Planta 2009, 230:85-94.

31. Li L, Cheng X, Ling HQ: Isolation and characterization of Fe(III)-chelate reductase gene LeFRO1 in tomato. Plant Mol Biol 2004, 54:125-136.

32. Ling $H Q$, Bauer $P$, Bereczky Z, Keller B, Ganal M: The tomato fer gene encoding a bHLH protein controls iron-uptake responses in roots. Proc Natl Acad Sci USA 2002, 99:13938-13943.

33. Brumbarova T, Bauer P: Iron-mediated control of the basic helix-loophelix protein FER, a regulator of iron uptake in tomato. Plant Physiol 2005, 137:1018-1026

34. Bauer $P$, Thiel T, Klatte M, Bereczky Z, Brumbarova T, Hell R, Grosse I: Analysis of sequence, map position, and gene expression reveals conserved essential genes for iron uptake in Arabidopsis and tomato. Plant Physiol 2004, 136:4169-4183.

35. Yuan Y, Wu H, Wang N, Li J, Zhao W, Du J, Wang D, Ling HQ: FIT interacts with AtbHLH38 and AtbHLH39 in regulating iron uptake gene expression for iron homeostasis in Arabidopsis. Cell Res 2008, 18:385-397.

36. The Arabidopsis Information Resource. [http://www.arabidopsis.org]. 
37. Briat JF, Duc C, Ravet K, Gaymard F: Ferritins and iron storage in plants. Biochim Biophys Acta 2010, 1800:806-814.

38. Gollhofer J, Schläwicke C, Jungnick N, Schmidt W, Buckhout TJ: Members of a small family of nodulin-like genes are regulated under iron deficiency in roots of Arabidopsis thaliana. Plant Physiol Biochem 2011, 49:557-564.

39. Espen L, Dell'Orto M, De Nisi P, Zocchi G: Metabolic responses in cucumber (Cucumis sativus L.) roots under Fe-deficiency: a ${ }^{31} \mathrm{P}$-nuclear magnetic resonance in vivo-study. Planta 2000, 210:985-992.

40. Zocchi G: Metabolic changes in iron-stressed dicotyledonous plants. In Iron nutrition in plants and rhizospheric microorganisms. Edited by: Barton LL, Abadía J. Dordrecht, Springer; 2007:359-370.

41. López-Millán AF, Morales F, Gogorcena Y, Abadía A, Abadía J: Metabolic responses in iron deficient tomato plants. J Plant Physiol 2009, 166:375-384

42. Scheidig A, Fröhlich A, Schulze S, Lloyd JR, Kossmann J: Down-regulation of a chloroplast-targeted beta-amylase leads to a starch-excess phenotype in leaves. Plant J 2002, 30:581-591.

43. López-Millán AF, Morales F, Andaluz S, Gogorcena Y, Abadía A, De Las Rivas J, Abadía J: Responses of sugar beet roots to iron deficiency. Changes in carbon assimilation and oxygen use. Plant Physiol 2000, 124:885-898.

44. Vigani G, Maffi D, Zocchi G: Iron availability affects the function of mitochondria in cucumber roots. New Phytol 2009, 182:127-136.

45. Kobayashi T, Nishizawa NK, Mori S: Iron nutrition in field crops. In Iron nutrition in plants and rhizospheric microorganisms.. 1 edition. Edited by: Barton LL, Abadia J. Dordrecht: Springer; 2007:395-435.

46. Kobayashi T, Suzuki M, Inoue H, Itai RN, Takahashi M, Nakanishi H, Mori S, Nishizawa NK: Expression of iron-acquisition-related genes in irondeficient rice is co-ordinately induced by partially conserved irondeficiency-responsive elements. J Exp Bot 2005, 56:1305-1316.

47. Zheng L, Huang F, Narsai R, Wu J, Giraud E, He F, Cheng L, Wang F, Wu P, Whelan J, Shou H: Physiological and transcriptome analysis of iron and phosphorus interaction in rice seedlings. Plant Physiol 2009, 151:262-274.

48. Astolfi S, Zuchi S, Hubberten HM, Pinton R, Hoefgen R: Supply of sulphur to S-deficient young barley seedlings restores their capability to cope with iron shortage. J Exp Bot 2010, 61:799-806.

49. Mazzucotelli E, Mastrangelo AM, Crosatti C, Guerra D, Stanca AM, Cattivelli L: Abiotic stress response in plants: When post-transcriptional and post-translational regulations control transcription. Plant Sci 2008, 174:420-431.

50. Pontiggia A, De Nisi P, Zocchi G: Effect of iron deficiency on RNA and protein synthesis in cucumber roots. J Plant Nutr 2003, 10-11:2177-2186.

51. Römheld V, Marschner $\mathrm{H}$ : Mobilization of iron in the rhizosphere of different plant species. Adv Plant Nutr 1986, 2:155-204.

52. Tomasi N, Weisskopf L, Renella G, Landi L, Pinton R, Varanini Z, Nannipieri P, Torrent J, Martinoia E, Cesco S: Flavonoids of white lupin roots participate in phosphorus mobilization from soil. Soil Biol Biochem 2008, 40:1971-1974

53. Jin CW, You GY, He YF, Tang CX, Wu P, Zheng SJ: Iron-deficiency-induced secretion of phenolics facilitates the reutilization of root apoplastic iron in red clover (Trifolium pratense L.). Plant Physiol 2007, 144:278-285.

54. Masada S, Terasaka K, Oguchi Y, Okazaki S, Mizushima T, Mizukami H: Functional and structural characterization of a flavonoid glucoside 1,6glucosyltransferase from Catharanthus roseus. Plant Cell Physiol 2009, 50:1401-1415.

55. Cesco S, Neumann G, Tomasi N, Pinton R, Weisskopf L: Release of plantborne flavonoids into the rhizosphere and their role in plant nutrition. Plant Soil 2010, 329:1-25.

56. Machold O: Einfluss der Ernährungsbedingungen auf den Zustand des Eisens in den Blättern, den Chlorophyllgehalt und die Katalase- sowie Peroxydaseaktivität. Flora (Jena), Abt A 1968, 159:1-25.

57. Ranieri A, Castagna A, Baldan B, Soldatini GF: Iron deficiency differently affects peroxidase isoforms in sunflower. J Exp Bot 2001, 52:25-35.

58. Lou Y, Baldwin IT: Silencing of a germin-like gene in Nicotiana attenuata improves performance of native herbivores. Plant Physiol 2006, 140:1126-1136.

59. Römheld V, Marschner H: Iron deficiency stress induced morphological and physiological changes in root tips of sunflower. Physiol Plant 1981, 53:354-360.
60. Römheld V, Kramer D: Relationship between proton efflux and rhizodermal transfer cells induced by iron deficiency. Z Pflanzenphysiol 1983, 113:73-83

61. Schmidt W: Mechanisms and regulation of reduction-based iron uptake in plants. New Phytol 1999, 141:1-26.

62. Schikora A, Schmidt W: Iron stress-induced changes in root epidermal cell fate are regulated independently from physiological responses to low iron availability. Plant Physiol 2001, 125:1679-1687.

63. Schikora A, Schmidt W: Formation of transfer cells and $\left(\mathrm{H}^{+}\right)$-ATPase expression in tomato roots under P and Fe deficiency. Planta 2002, 215:304-311.

64. Bucher M, Brunner S, Zimmermann P, Zardi Gl, Amrhein N, Willmitzer L, Riesmeier JW: The expression of an extensin-like protein correlates with cellular tip growth in tomato. Plant Physiol 2002, 128:911-923.

65. Bucher M, Schroeer B, Willmitzer L, Riesmeier JW: Two genes encoding extension-like proteins are predominantly expressed in tomato root hair cells. Plant Mol Biol 1997, 35:497-508.

66. Cosgrove DJ: Enzymes and other agents that enhance cell wall extensibility. Annu Rev Plant Physiol Plant Mol Biol 1999, 50:391-417.

67. Chen CY, Wong El, Vidali L, Estavillo A, Hepler PK, Wu HM, Cheung AY: The regulation of actin organization by actin-depolymerizing factor in elongating pollen tubes. Plant Cell 2002, 14:2175-2190.

68. Bots $M$, Vergeldt $F$, Wolters-Arts $M$, Weterings $K$, van As $H$, Mariani C: Aquaporins of the PIP2 class are required for efficient anther dehiscence in tobacco. Plant Physiol 2005, 137:1049-1056.

69. Wintz H, Fox T, Wu YY, Feng V, Chen W, Chang HS, Zhu T, Vulpe Expression Profiles of Arabidopsis thaliana in Mineral Deficiencies Reveal Novel Transporters Involved in Metal Homeostasis. J Biol Chem 2003, 278:47644-47653.

70. Lubkowitz M: The oligopeptide transporters: a small gene family with a diverse group of substrate and functions? Mol Plant 2011, 4:407-415

71. Stacey MG, Osawa H, Patel A, Gassmann W, Stacey G: Expression analyses of Arabidopsis oligopeptide transporters during seed germination, vegetative growth and reproduction. Planta 2006, 223:291-305.

72. Vasconcelos MW, Li GW, Lubkowitz MA, Grusak MA: Characterization of the PT clade of oligopeptide transporters in rice. Plant Genome 2008, 1:77-88.

73. Lauter FR, Ninnemann O, Bucher M, Riesmeier JW, Frommer WB: Preferential expression of an ammonium transporter and of two putative nitrate transporters in root hairs of tomato. Proc Natl Acad Sci USA 1996, 93:8139-8144.

74. von Wirén N, Lauter FR, Ninnemann O, Gillissen B, Walch-Liu P, Engels C, Jost W, Frommer WB: Differential regulation of three functional ammonium transporter genes by nitrogen in root hairs and by light in leaves of tomato. Plant J 2000, 21:167-175.

75. Tomson CJ, Marschner $\mathrm{H}$, Römheld V: Effect of nitrogen fertilizer form on $\mathrm{pH}$ of the bulk soil and rhizosphere, and on the growth, phosphorous, and micronutrient uptake of bean. J Plant Nut 1993, 16:493-506.

76. Nikolic M, Cesco S, Römheld V, Varanini Z, Pinton R: Short-term interactions between nitrate and iron nutrition in cucumber. Funct Plant Biol 2007, 34:402-408.

77. Kovermann P, Meyer S, Hörtensteiner S, Picco C, Scholz-Starke J, Ravera S, Lee Y, Martinoia E: The Arabidopsis vacuolar malate channel is a member of the ALMT family. Plant J 2007, 52:1169-1180.

78. Abadía J, López-Millán AF, Rombolà A, Abadía A: Organic acid and Fe deficiency: a review. Plant Soil 2002, 241:75-86.

79. Romera FJ, Lucena C, Alcàntara E: Plant hormones influencing iron uptake in plants. In Iron nutrition in plants and rhizospheric microorganisms.. 1 edition. Edited by: Barton LL, Abadia J. Dordrecht: Springer; 2007:251-278.

80. Romera FJ, García MJ, Alcántara E, Pérez-Vicente R: Latest findings about the interplay of auxin, ethylene and nitric oxide in the regulation of $\mathrm{Fe}$ deficiency responses by Strategy I plants. Plant Signal Behav 2011, 6:167-170.

81. van der Merwe MJ, Osorio S, Moritz T, Nunes-Nesi A, Fernie AR: Decreased mitochondrial activities of malate dehydrogenase and fumarase in tomato lead to altered root growth and architecture via diverse mechanisms. Plant Physiol 2009, 149:653-669.

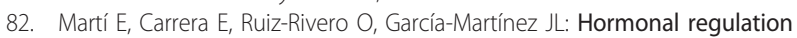
of tomato gibberellin 20-oxidase1 expressed in Arabidopsis. J Plant Physiol 2010, 167:1188-1196. 
83. Séguéla $M$, Briat JF, Vert $G$, Curie C: Cytokinins negatively regulate the root iron uptake machinery in Arabidopsis through a growth-dependent pathway. Plant J 2008, 55:289-300.

84. Werner T, Köllmer I, Bartrina I, Holst K, Schmülling T: New insights into the biology of cytokinin degradation. Plant Biol 2006, 8:371-381.

85. Miyazaki S, Koga R, Bohnert HJ, Fukuhara T: Tissue- and environmental response-specific expression of 10 PP2C transcripts in Mesembryanthemum crystallinum. Mol Gen Genet 1999, 261:307-316.

86. Guo Y, Halfter U, Ishitani M, Zhu JK: Molecular characterization of functional domains in the protein kinase SOS2 that is required for plant salt tolerance. Plant Cell 2001, 13:1383-1400.

87. Gong D, Guo Y, Schumaker KS, Zhu JK: The SOS3 family of calcium sensors and SOS2 family of protein kinases in Arabidopsis. Plant Physiol 2004, 134:919-926.

88. Navarro L, Zipfel C, Rowland O, Keller I, Robatzek S, Boller T, Jones JD: The transcriptional innate immune response to flg22. Interplay and overlap with Avr gene-dependent defense responses and bacterial pathogenesis. Plant Physiol 2004, 135:1113-1128.

89. Pinton R, Cesco S, Santi S, Agnolon F, Varanini Z: Water-extractable humic substances enhance iron deficiency responses by Fe-deficient cucumber plants. Plant Soil 1999, 210:145-157.

90. Functional Genomic Center. [http://ddlab.sci.univr.it/FunctionalGenomics].

91. Rouillard JM, Zuker M, Gulari E: OligoArray 2.0: design of oligonucleotide probes for DNA microarrays using a thermodynamic approach. Nucleic Acid Res 2003, 31:3057-3062.

92. The DFCl Tomato Gene Index. [http://compbio.dfci.harvard.edu/tgi/cgi-bin/ tgi/gimain.pl?gudb=tomato].

93. Gene Expression Omnibus. [http://www.ncbi.nlm.nih.gov/geo].

94. Gentleman RC, Carey VJ, Bates DM, Bolstad B, Dettling M, Dudoit S, Ellis B, Gautier L, Ge Y, Gentry J, Hornik K, Hothorn T, Huber W, lacus S, Irizarry R, Leisch F, Li C, Maechler M, Rossini AJ, Sawitzki G, Smith C, Smyth G, Tierney L, Yang JY, Zhang J: Bioconductor: open software development for computational biology and bioinformatics. Genome Biol 2004, 5:R80.

95. The Bioconductor project. [http://www.bioconductor.org/]

96. Ihaka R, Gentleman R: R: A language for data analysis and graphics. J Comput Graph Stat 1996, 5:299-314.

97. The R Project for Statistical Computing. [http://www.r-project.org/].

98. Altschul SF, Madden TL, Schäffer AA, Zhang J, Zhang Z, Miller W, Lipman DJ: Gapped BLAST and PSI-BLAST: a new generation of protein database search programs. Nucleic Acid Res 1997, 25:3389-3402.

99. The pqcR library. [http://www.dr-spiess.de/qpcR.html].

100. Ritz C, Spiess AN: qpcR: an R package for sigmoidal model selection in quantitative realtime polymerase chain reaction analysis. Bioinformatics 2008, 24:1549-155.

\section{Submit your next manuscript to BioMed Central and take full advantage of:}

- Convenient online submission

- Thorough peer review

- No space constraints or color figure charges

- Immediate publication on acceptance

- Inclusion in PubMed, CAS, Scopus and Google Scholar

- Research which is freely available for redistribution

Submit your manuscript at www.biomedcentral.com/submit 